\title{
Discriminating Five Forms of Job Satisfaction: Investigating Their Relevance for Occupational Health Research and Practice
}

\author{
Alice Inauen, Gregor J. Jenny, Georg F. Bauer \\ Epidemiology, Biostatistics, and Prevention Institute, Division of Public \& Organizational Health, University of \\ Zurich, Zurich, Switzerland \\ Email: alice.inauen@ifspm.uzh.ch
}

Received 6 January 2015; accepted 26 January 2015; published 29 January 2015

Copyright (C) 2015 by authors and Scientific Research Publishing Inc.

This work is licensed under the Creative Commons Attribution International License (CC BY). http://creativecommons.org/licenses/by/4.0/

c) (i) Open Access

\begin{abstract}
This study analyzed the relation and discrimination between five forms of job satisfaction (stabilized, progressive and resigned satisfaction; constructive and fixated dissatisfaction) regarding health, work-related determinants of health and demographic variables. Job satisfaction was assessed with a forced-choice survey item in 10 Swiss companies (768 employees). Significant differences between forms of job satisfaction with respect to health status, effort-reward imbalance, job control, work engagement, age and sex were found. The five forms of job satisfaction were discriminated, but classifying only $49.9 \%$ of the cases correctly. General utility of this forced-choice item therefore must be relativized.
\end{abstract}

\section{Keywords}

Forms of Job Satisfaction, Health, Effort-Reward Imbalance, Job Control, Work Engagement, Occupational Health Research and Practice

\section{Introduction}

Job satisfaction is an important concept in occupational health research and practice, as it is positively correlated to health and well-being (Faragher, Cass, \& Cooper, 2005). It is commonly measured with an "overall job satisfaction” assessment in employee surveys that tend to result in high positive values, providing little guidance for interventions (Büssing, 1992; Büssing, Bissels, Fuchs, \& Perrar, 1999). As an alternative, Bruggemann (1974, 
1976) proposed a model with five different forms of job satisfaction: stabilized, progressive, and resigned satisfaction, plus constructive and fixated dissatisfaction. The model is well-known in German speaking countries, but little known in English speaking countries (Büssing et al., 1999). Büssing et al. (1992, 1998, 1999, 2002) published some empirical works, further contributing to the clarification of the concept. The present paper examines the potential of distinguishing five different forms of job satisfaction for the field of occupational health research and practice.

\subsection{The Job Satisfaction Model of Bruggemann}

Bruggemann $(1974,1976)$ assumed that job satisfaction is characterized by different dynamic motivational structures. The five forms of job satisfaction result from three successive processes (Figure 1): First, the present work situation is compared to personal aspirations. Stabilized satisfaction or indistinct dissatisfaction develops, depending on the congruence between the present work situation and personal aspirations. Second, readjustment of the level of aspiration may occur (increase or decrease), or the level of aspiration may be maintained. Third, if the level of aspiration is maintained in a state of dissatisfaction, problem-solving behavior is initiated to change the work situation (Bruggemann, 1974; Büssing, 1992; Büssing et al., 1999).

Bruggemann (1974) described the five forms of job satisfaction as follows (cited and translated in: Büssing, 2002; Büssing et al., 1999):

- Stabilized job satisfaction: A person feels satisfied with his/her work, but is motivated to maintain his/her level of aspiration and pleasurable state of satisfaction.

- Progressive job satisfaction: A person feels satisfied with his/her work. By increasing the level of aspiration, he/she tries to achieve an even higher level of satisfaction.

- Resigned job satisfaction: A person feels indistinct work dissatisfaction and decreases his/her level of aspiration in order to adapt to negative aspects of the work situation on a lower level. By decreasing his/her level of aspiration, a person is able to achieve a state of satisfaction again.

- Constructive job dissatisfaction: A person feels dissatisfied with his/her work. While maintaining his/her level of aspiration, he/she tries to master the situation by problem-solving attempts.

- Fixated job dissatisfaction: A person feels dissatisfied with his/her work. He/she maintains his/her level of aspiration, and does not try to master the situation by problem-solving attempts.

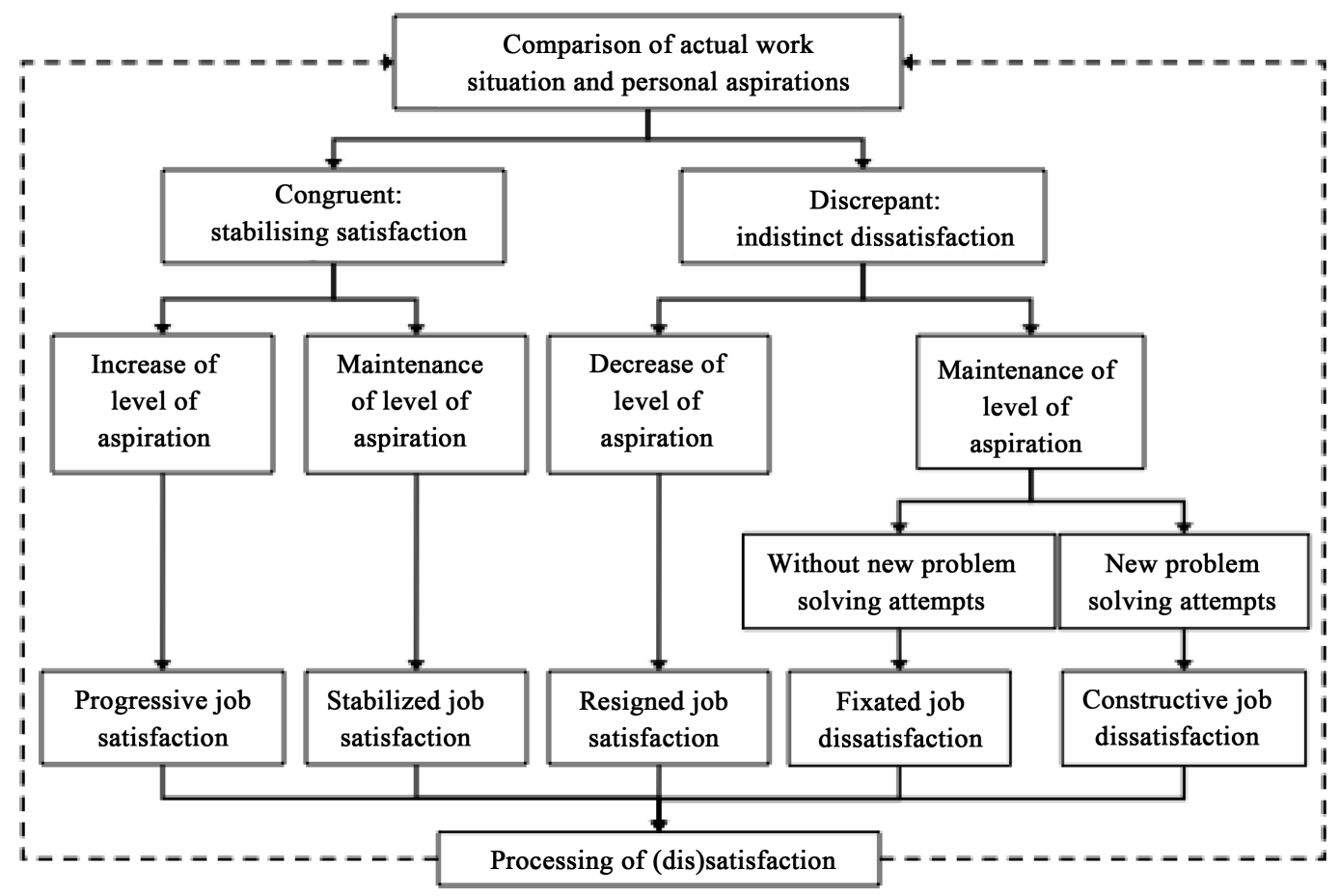

Figure 1. Forms of job satisfaction (adapted from: Bruggemann, 1974; Büssing et al., 1999). 


\subsection{Previous Research on the Job Satisfaction Model}

Attempts to replicate Bruggemann's model often resulted in modifications of the model. This can be explained with different operationalizations, making it difficult to compare results and the difficulty to capture the dynamic changes in level of aspiration (Baumgartner \& Udris, 2006). Büssing et al. (1992, 1998, 1999) analyzed the dynamics of the model and expanded the model integrating job control as an additional process variable for the regulation of the work situation and thus for development of job satisfaction. Although the results of previous replication studies were inconsistent, most of them found two dimensions: general job satisfaction and resignation. Some researchers consequently minimized the model, using only these two dimensions (Baumgartner \& Udris, 2006). Nevertheless, the five forms of job satisfaction according to Bruggemann (1976) are often used in employee surveys, especially in Switzerland and Germany. A market-research institute (TransferPlus AG, 2013) has applied the model since 1979, conducting a survey in a representative sample of the Swiss population (Figure 2). Stabilized and resigned forms of job satisfaction were most prevalent, but they show a relatively high variability over time.

In view of the dynamics of the model, interviews would be the preferred method of measuring the different forms of job satisfaction. However, Bruggemann (1976) stated that assessing forms of job satisfaction by interviews limits the utilization of the construct in larger samples and consequently developed a job satisfaction short questionnaire (Arbeitszufriedenheitskurzfragebogen, AZK). This was criticized for its operation alization (Baumgartner \& Udris, 2006; Ferreira, 2009). Büssing et al. (1992, 1998, 1999) adapted this scale and combined it with interviews. The most recent questionnaire, the FEAT, was developed by Ferreira (2009) and contains 80 items. Forms of job satisfaction can also be assessed with a forced-choice item designed for field studies (TransferPlus AG, 2013). Even though this forced-choice format is critical for the measurement of such a multidimensional construct, validation showed that this forced-choice item is a simple and adequate way to measure the job satisfaction forms (Ziegler \& Schlett, 2013). Compared to multi-item measures, the single forced-choice format has the advantage of being more feasible in employee surveys and having higher face validity for respondents. Research has also proved the validity of single-item measures for job satisfaction (Nagy, 2002; Wanous, Reichers, \& Hudy, 1997). The forced-choice format provides a clear group classification, but involves a higher risk of choosing an unconsidered option and comparisons across individuals are limited (Baron, 1996).

\subsection{Study Objectives}

The objective of this study was to determine whether the five forms of job satisfaction-assessed by a forcedchoice item-are differentially related to health status and three work-related determinants of health: effortreward imbalance (ERI), job control and work engagement. This would allow occupational health interventions to be prioritized and tailored to such sub-groups. We pursued four main research questions:

1) Are these five forms of job satisfaction differentially related to health status?

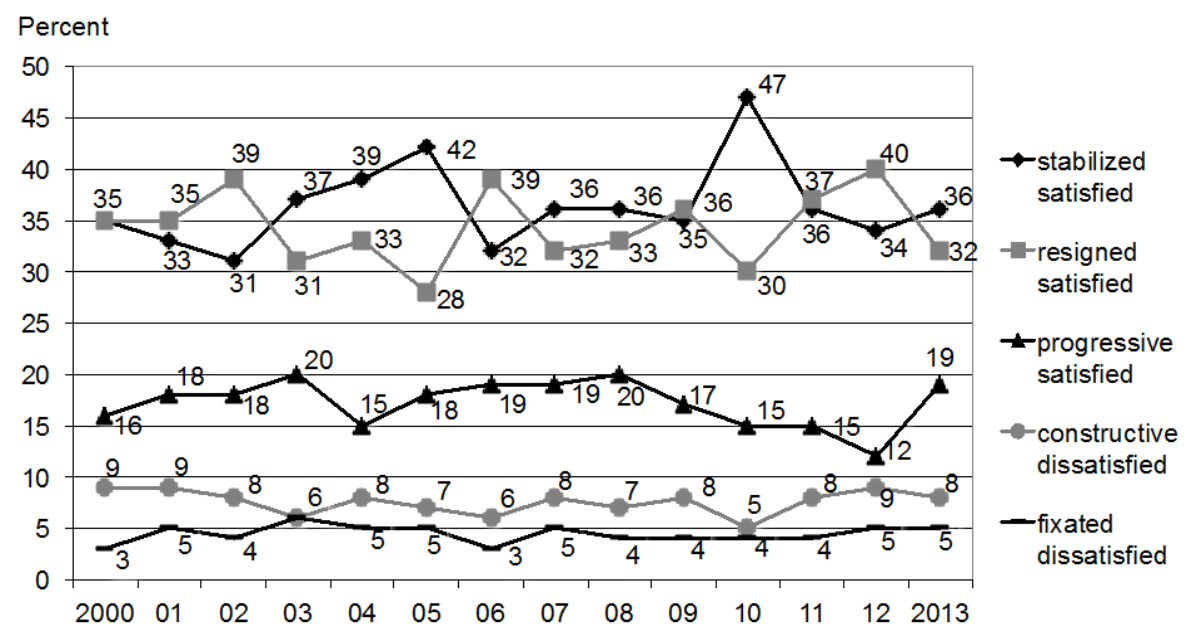

Figure 2. Forms of job satisfaction in Switzerland 2000-2013 (TransferPlus AG, 2013). 
2) How are these five forms of job satisfaction related to ERI, job control and work engagement?

3) How are these five forms of job satisfaction related to the demographic variables of age, sex and job position?

4) Is it possible to discriminate between these five forms of the job satisfaction by ERI, job control and work engagement?

Finally, we draw conclusions for occupational health research and interventions.

\section{Previous Research on Differential Relationships to Different Forms of Job Satisfaction}

\subsection{Job Satisfaction Forms and Health}

Consistent and significant positive correlations between general job satisfaction and health or well-being were found (Faragher et al., 2005). Regarding the forms of job satisfaction, Bruggemann (1974) stated in her description of fixated dissatisfaction that pathological developments could occur. This has been confirmed by Semmer (2002) in different samples. He found more health complaints for the dissatisfied forms. Wegge and Neuhaus (2002) conducted a study with 68 employees of a German university. The constructively dissatisfied group also reported more health complaints, while the stabilized satisfied group reported the lowest level of health complaints.

Hypothesis 1: Stabilized and progressive satisfied show the best health status, constructive dissatisfied and resigned satisfied show lower health status and fixated dissatisfied employees show the worst health status.

\subsection{Job Satisfaction Forms and Work-Related Determinants of Health}

The ERI model assumes that effort at work is part of a contract based on the norm of social reciprocity, where rewards are provided in terms of money, esteem, career opportunities, and job security (Siegrist et al., 2004). A lack of reciprocity causes negative emotions which may result in sustained strain reactions in the autonomic nervous system (Siegrist et al., 2004). Empirical results confirmed that an imbalance between effort and reward is related to poor employee health and lower general job satisfaction (Van Vegchel, De Jonge, Bosma, \& Schaufeli, 2005). Also Bruggemann (1974) described a process of comparison between the actual work situation and personal aspirations. Thus, we expect ERI to differ between the five forms of job satisfaction.

Hypothesis 2.1: ERI relates to indistinct dissatisfaction (constructive and fixated job dissatisfaction), while stabilized and progressive satisfied employees have a better balance. Average values are expected for the resigned form of job satisfaction due to an adjustment in the level of aspiration.

Job control is defined as the perceived ability to influence one's work environment in order to make it more rewarding and less threatening (Ganster, 1989; cited in: Bond \& Bunce, 2003). There is consistent evidence that job control is related to general job satisfaction, health and job performance (Bond \& Bunce, 2003; Karasek, 1990). Büssing (1992) and Büssing et al. $(1998,1999)$ integrated job control as a fourth variable in Bruggemann's model, as the perceived controllability of one's work situation is a primary means of regulating the situation. They found higher job control for stabilized and progressive job satisfaction and for constructive job dissatisfaction. Resigned satisfaction seemed to be a reaction to low job control (Büssing, Herbig, Bissels, \& Krüsken, 2006). Wegge and Neuhaus (2002) explored differences between the forms of job satisfaction and working conditions. Progressive satisfied showed the highest, constructive dissatisfied the lowest job control at work. Baumgartner and Udris (2006) investigated the forms and determinants of job satisfaction and found the highest values of perceived control for the stabilized satisfied group, average values for the progressive satisfied group and the lowest values for the resigned satisfied and fixated dissatisfied groups. In the present study, we view job control as a resource that allows the level of aspiration to be maintained or even increased and supports new problem-solving attempts.

Hypothesis 2.2: Stabilized satisfied, progressive satisfied or constructive dissatisfied employees perceive higher job control than resigned satisfied or fixated dissatisfied employees.

Work engagement is defined as a positive, fulfilling, work-related state of mind that is characterized by vigor, dedication, and absorption. It is a persistent affective-cognitive state that is not focused on any particular object, event, individual, or behavior (Schaufeli \& Bakker, 2003). Schaufeli, Taris and van Rhenen (2008) found that work engagement was related to positive work outcomes like general job satisfaction as well as to health out- 
comes. Empirical results for differences between forms of job satisfaction exist only for the related variables of organizational identification and citizenship behavior. The constructive dissatisfied group expressed high, the resigned satisfied group low organizational identification and citizenship behavior (Wegge \& Neuhaus, 2002). As engaged employees were more energetic and effective in their work activities (Schaufeli et al., 2008), we expect an association with progressive job satisfaction and constructive job dissatisfaction.

Hypothesis 2.3: Progressive job satisfaction and constructive job dissatisfaction indicate higher work engagement. We expect lower levels of work engagement from stabilized satisfied, resigned satisfied and fixated dissatisfied employees.

\subsection{Forms of Job Satisfaction and Demographic Variables}

Demographic variables play a role in both job satisfaction and the planning of occupational health interventions. Subgroups are often compared in planning interventions. It is important to know if differences in job satisfaction are due merely to different demographic compositions of the groups. As regards general measures of job satisfaction, it is debated whether the relationship with age is U-shaped or linear. Older employees (Clark, Oswald, \& Warr, 1996), women and employees in jobs with managerial responsibility usually report higher levels of job satisfaction (Clark, 1997). For the forms of job satisfaction, previous results showed that the members of the progressive satisfied group tended to be male, younger, better educated, and have higher professional position (Bruggemann, 1976; TransferPlus AG, 2013; Wegge \& Neuhaus, 2002). Women, older employees and people with lower incomes and of low status were overrepresented in the stabilized satisfied group (Bruggemann, 1976; TransferPlus AG, 2013; Wegge \& Neuhaus, 2002). The resigned satisfied group had lower levels of education (Bruggemann, 1976; TransferPlus AG, 2013). In the constructive dissatisfied group, men were overrepresented (Bruggemann, 1976).

Hypothesis 3: Progressive satisfied employees tend to be male, younger and in higher positions, whereas stabilized satisfied ones tend to be female, older and in lower positions. No specific hypotheses are formulated for the other forms of job satisfaction.

\section{Discrimination between Forms of Job Satisfaction}

We expect to see differences between the forms of job satisfaction. We analyze the overall discriminatory function of ERI, job control and work engagement with respect to the five forms of job satisfaction.

Hypothesis 4: The five forms of job satisfaction can be discriminated by ERI, job control and work engagement.

\section{Methods}

\subsection{Sample and Data Collection}

Data was collected via an employee survey in ten companies in German-speaking Switzerland participating in an occupational health project. The companies were small and medium-sized, ranging from 13 to 335 employees. They were from different sectors (public administration, nursery, rehabilitation, nursing home, health consultancy, production), and most of them (85\%) were non-profit organizations. Of the total of 768 employees, 537 completed the survey (69.9\% response rate): $60.7 \%$ of the respondents were female, different age groups and job positions were represented (Table 1).

\subsection{Measures}

Forms of job satisfaction (according to Bruggemann, 1976) were assessed with a forced-choice item designed for field studies (TransferPlus AG, 2013). The use of this item allows comparison with data that is representative for the Swiss population. The item is formulated as follows:

Which description on this list applies to you most?

- I'm satisfied with my job-I tell myself, it could be a lot worse. (Resigned satisfied)

- I'm not satisfied with my job because some important points annoy me. I believe, though, that some of these points will change in the future. (Constructive dissatisfied)

- I'm really satisfied with my job and just wish for everything to stay this good in the near future. (Stabilized satisfied) 
Table 1. Forms of job satisfaction: age, sex and job position.

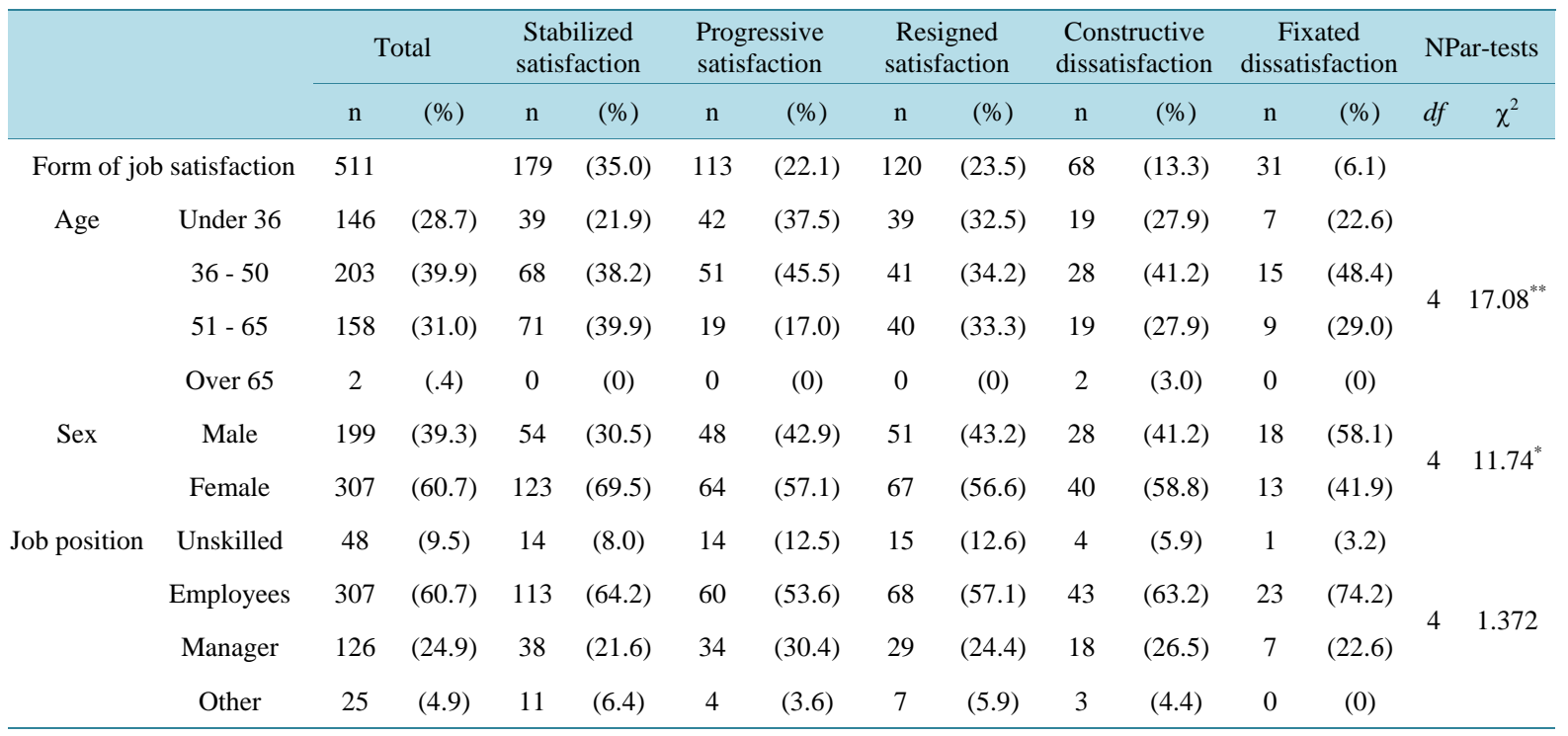

Note: Non-parametric tests (Kruskal-Wallis), ${ }^{*} p<.05 ;{ }^{* *} p<.01$; “Other” were excluded.

- Somehow I'm dissatisfied with my job but I don't know what I should do either. (Fixated dissatisfied)

- I'm really satisfied with my job-in particular because I can still advance further in it. (Progressive satisfied)

The health status was measured with the validated German version of the SF-12v2 Health Survey (2000), (Gandek et al., 1998), assessing the self-reported health. The reliability for physical health was $\alpha=.77$, for mental health it was $\alpha=.80$. The physical and mental health summary scores were calculated as proposed in the manual, transforming scores to a mean of $50(S D=10)$ (Ware, Kosiniski, Turner-Bowker, \& Gandek, 2002). In addition to the standardized summary scores, the item for general health perception was scored separately for analysis: "In general, would you say your health is..." on a 5-point scale from $1=$ "excellent" to $5=$ "poor". We considered this item as a separate measure, as self-rated health is a good predictor of future morbidity (Moller, Kristensen, \& Hollnagel, 1996).

ERI was assessed with the questionnaire by Siegrist and Peter (1996), English version, see Siegrist et al., (2004). Totally 17 items measure effort (quantitative load, qualitative load, increase in total load over time and physical load, $\alpha=.72$ ) and reward (financial, esteem, career-related reward and job security, $\alpha=.81$ ). The effort-reward ratio was computed. Values close to zero indicate a good balance, whereas values beyond 1 indicate an imbalance.

Job control was measured with four items: "Independent and flexible scheduling of working hours", "Information on key matters and occurrences in the company", "Opportunity to have a say in company decisions", "Opportunity for exercising an influence on problems at the workplace" using a 5-point scale from 1 = "very poor" to 5 = "very good" or the option to answer "not applicable". These items are part of a widespread standard survey that is used in the field for employee surveys in small and medium enterprises in Switzerland (Gesundheitsfoerderung Schweiz, 2004). A scale was devised by computing the mean $(\alpha=.77)$, and treating the response item "not applicable” as a missing answer.

For measurement of work engagement, the short version of the Utrecht Work Engagement Scale (UWES-9) from Schaufeli and Bakker (2003) was applied. Three items of the UWES-9 assess vigor, three items assess dedication and three items assess absorption. Items were rated on a 7-point scale, ranging from $0=$ "never" to $6=$ "always". The mean total score was computed $(\alpha=.94)$.

\subsection{Data Analysis}

We conducted analyses of variance and post-hoc tests comparing the groups of different job satisfaction forms with respect to health, ERI, job control and work engagement. We used U-Tests, testing for demographic differences between the five groups. In applying multiple discriminant analysis, the five forms of job satisfaction 
were discriminated by the variables of ERI, job control and work engagement. Uncorrelated functions were computed for which the group means were as different as possible. All analyses were conducted using SPSS 17.0.1 (2008).

\section{Results}

\subsection{Descriptive Results}

Compared to the sample of the Swiss population (Figure 2), there were more progressive satisfied (22\%) and less resigned satisfied (24\%) employees in our sample. The frequency distribution for age, sex and job position for the forms of job satisfaction is shown in Table 1. A higher age was found for stabilized satisfaction and a lower one for progressive satisfaction. The stabilized satisfied were more often female and the fixated dissatisfied more often male. The highest percentage of managers was found in the progressive satisfaction group, whereas employees without leadership responsibility were most prevalent in the fixated dissatisfaction group.

Table 2 includes the descriptive results of the health variables and the work-related determinants of health for the five forms of job satisfaction. With some exceptions, a linear pattern from progressive satisfied (with the best results) to fixated dissatisfied (with the poorest results) is apparent. The total mean for physical health was $52.12(S D=7.13)$, for mental health $48.78(S D=10.67)$ and for general health $48.48(S D=8.99)$. The total mean of the ERI was $.56(S D=.24)$, the mean job control was $3.69(S D=.76)$ and the overall mean of the total score on the work engagement scale was $5.16(S D=1.10)$.

Tests of normality distribution showed that data manipulation was needed. For ERI, a logarithmic transformation was used, improving the statistical power (Siegrist et al., 2004). For work engagement, five categories were defined (Schaufeli \& Bakker, 2003). Correlations between variables were as expected (see Table 3). Highest correlations were found between forms of job satisfaction and work-related determinants of health (ERI, job control, work engagement).

\subsection{Differences between the Five Forms of Job Satisfaction and Health (Hypothesis 1)}

The differences in health status between the five forms of job satisfaction are partly significant (see Table 2). The group means for physical health differed with a $F(4,485)=2.508$ and $p<.05$. Mental health differed with a $F(4,485)=2.378$ and $p=.051$ and therefore showed a marginal significance. Highly significant differences in the group means were found for general health perception $(F(4,502)=5.553, p<.001)$. Post-hoc tests revealed significant better physical health for the progressive satisfied compared to the constructive dissatisfied employees $(p<.05)$. In addition, the progressive satisfied employees showed significantly better general health than the fixated dissatisfied $(p<.001)$ and constructive dissatisfied ones $(p<.05)$. The stabilized satisfied showed significantly better general health than the fixated dissatisfied employees $(p<.01)$.

These results partly confirm Hypothesis 1 . The expected high values for the stabilized satisfied group were found, and this form had the best mental health scores. We expected good health status for the progressive satisfied group, which was true for physical health and general health perception. However, they showed only moderate

Table 2. Forms of job satisfaction: health, ERI, job control and work engagement.

\begin{tabular}{|c|c|c|c|c|c|c|c|c|c|c|c|c|c|c|}
\hline \multirow[b]{2}{*}{ Variable } & \multicolumn{2}{|c|}{ Total } & \multicolumn{2}{|c|}{$\begin{array}{l}\text { Stabilized } \\
\text { satisfaction }\end{array}$} & \multicolumn{2}{|c|}{$\begin{array}{l}\text { Progressive } \\
\text { satisfaction }\end{array}$} & \multicolumn{2}{|c|}{$\begin{array}{c}\text { Resigned } \\
\text { satisfaction }\end{array}$} & \multicolumn{2}{|c|}{$\begin{array}{l}\text { Constructive } \\
\text { dissatisfaction }\end{array}$} & \multicolumn{2}{|c|}{$\begin{array}{c}\text { Fixated } \\
\text { dissatisfaction }\end{array}$} & \multicolumn{2}{|c|}{ ANOVA } \\
\hline & Mean & $S D$ & Mean & $S D$ & Mean & $S D$ & Mean & $S D$ & Mean & $S D$ & Mean & $S D$ & $d f$ & $F$ \\
\hline Physical health & 52.12 & 7.13 & 52.03 & 6.16 & 53.81 & 5.90 & 52.02 & 7.49 & 50.98 & 8.94 & 50.59 & 9.40 & 4, 485 & $2.51^{*}$ \\
\hline Mental health & 48.78 & 10.67 & 50.33 & 10.19 & 48.10 & 8.64 & 47.36 & 10.53 & 48.65 & 12.73 & 45.17 & 13.64 & 4, 485 & $2.38^{0}$ \\
\hline $\begin{array}{c}\text { General health } \\
\text { (1 item) }\end{array}$ & 48.48 & 8.99 & 48.98 & 9.08 & 50.75 & 8.10 & 48.11 & 7.87 & 46.56 & 9.52 & 43.33 & 11.81 & 4, 502 & $5.55^{* * *}$ \\
\hline $\begin{array}{l}\text { Effort-reward } \\
\text { imbalance }\end{array}$ & .56 & .24 & .48 & .19 & .48 & .20 & .58 & .22 & .74 & .27 & .71 & .23 & 4, 431 & $22.20^{* * *}$ \\
\hline Job control & 3.69 & .76 & 3.93 & .59 & 4.07 & .54 & 3.41 & .74 & 3.25 & .78 & 3.03 & .93 & 4, 506 & $35.76^{* * *}$ \\
\hline Work engagement & 5.16 & 1.10 & 5.49 & .80 & 5.73 & .75 & 4.67 & 1.11 & 4.74 & 1.36 & 3.85 & 1.03 & 4,475 & $23.96^{* * * *}$ \\
\hline
\end{tabular}

Note: ANOVA tests of equality of group means: ${ }^{0} p<.1,{ }^{*} p<.05,{ }^{* * *} p<.01,{ }^{* * *} p<.001$. 
Table 3. Correlations.

\begin{tabular}{|c|c|c|c|c|c|c|c|c|c|c|c|}
\hline & & 1 & 2 & 3 & 4 & 5 & 6 & 7 & 8 & 9 & 10 \\
\hline 1 & Form of job satisfaction (see notes) & 1 & & & & & & & & & \\
\hline 2 & Age $(1=$ under $36,2=36-50,3=51-65,4=$ over 65$)$ & $.09^{*}$ & 1 & & & & & & & & \\
\hline 3 & Sex $(1=$ male, 2 = female $)$ & $.12^{* *}$ & $-.10^{* *}$ & 1 & & & & & & & \\
\hline 4 & Job position ( 1 = unskilled, 2 = employee, $3=$ manager $)$ & .01 & $.22^{* *}$ & $-.20^{* *}$ & 1 & & & & & & \\
\hline 5 & Physical health & .02 & $-.23^{* *}$ & $-.08^{*}$ & -.01 & 1 & & & & & \\
\hline 6 & Mental health & $.14^{* *}$ & $.22^{* *}$ & $.07^{*}$ & .06 & $-.60^{* *}$ & 1 & & & & \\
\hline 7 & General health (1 item) & $.16^{* *}$ & $-.17^{* *}$ & -.04 & .02 & $.66^{* *}$ & $-.09^{*}$ & 1 & & & \\
\hline 8 & Effort-reward imbalance (see notes) & $-.37^{* *}$ & $.16^{* *}$ & $-.18^{* *}$ & $.28^{* *}$ & $-.21^{* *}$ & -.01 & $-.25^{* *}$ & 1 & & \\
\hline 9 & Job control & $.40^{* *}$ & -.02 & .01 & $.17^{* *}$ & $.11^{* *}$ & $.12^{* * *}$ & $.19^{* *}$ & $-25^{* *}$ & 1 & \\
\hline 10 & Work engagement & $.33^{* *}$ & $.09^{* *}$ & .06 & .04 & $.07^{*}$ & $.19^{* *}$ & $.17^{* *}$ & $-.15^{* *}$ & $.38^{* *}$ & 1 \\
\hline
\end{tabular}

Note: Form of job satisfaction: 1 = fixated dissatisfaction, 2 = constructive dissatisfaction, 3 = resigned satisfaction, 4 = progressive satisfaction, 5 = stabilized satisfaction; effort-reward imbalance: values close to zero indicate a good balance, ${ }^{*} p<.05,{ }^{* *} p<.01$.

mental health. The resigned satisfied and constructive dissatisfied groups were expected to show moderate health, which was found. As hypothesized, the fixated dissatisfied employees showed the poorest health status.

\subsection{Differences between the Five Forms of Job Satisfaction and Work-Related Determinants of Health (Hypothesis 2)}

The five forms of job satisfaction showed highly significant differences in the group means for ERI $(F(4,431)=$ $22.203, p<.001)$, job control $(F(4,506)=35.757, p<.001)$ and work engagement $(F(4,475)=23.963, p<.001)$ (see Table 2).

The stabilized and progressive satisfied groups showed significantly better ERI (i.e. lower values) than the resigned satisfied $(p<.01)$, constructive dissatisfied $(p<.001)$, and fixated dissatisfied $(p<.001)$ groups. This confirmed Hypothesis 2.1.

As expected for job control too, the stabilized and progressive satisfied groups showed significantly higher values than the resigned satisfied $(p<.001)$, constructive dissatisfied $(p<.001)$, and fixated dissatisfied ( $p$ $<.001$ ) groups. Contrary to our hypothesis, the resigned satisfied showed more job control than the constructive dissatisfied $(p<.01)$ group. Therefore, Hypothesis 2.2 can be only partly supported.

For work engagement, the stabilized and progressive satisfied groups showed significantly higher values than the resigned satisfied $(p<.01 / p<.001)$, constructive dissatisfied $(p<.001)$, and fixated dissatisfied $(p<.001)$ groups. In addition, the resigned and constructive (dis)satisfied showed higher work engagement values than the fixated dissatisfied $(p<.05)$ group. This only partly confirms Hypothesis 2.3. As expected, the constructive dissatisfied group showed higher work engagement than the resigned satisfied or fixated dissatisfied ones. But we did not expect the stabilized satisfied group to show high work engagement.

\subsection{Differences between the Five Forms of Job Satisfaction with Respect to Demographic Variables (Hypothesis 3)}

Significant differences in the group means were found for age $\left(\chi^{2}(4)=17.084, p<.01\right)$ and $\operatorname{sex}\left(\chi^{2}(4)=11.739\right.$, $p<.05$ ), but not for job position $\left(\chi^{2}(4)=1.372, p=.849\right.$ ) (see Table 1$)$. Mann-Whitney U-Test post-hoc comparisons showed that the progressive satisfied were significantly younger than the stabilized satisfied $(p<.001)$, resigned satisfied $(p<.05)$ and constructive dissatisfied $(p<.05)$ employees. Tests also showed that the stabilized satisfied were more often female than the fixated dissatisfied $(p<.01)$ and resigned satisfied $(p<.05)$ employees. In addition, the progressive satisfied group included more males than the stabilized satisfied $(p<.05)$ group. These findings are consistent with previous results with the exception of the non-significant differences for job position. Therefore, Hypothesis 3 is partly supported. 


\subsection{Discriminatory Function of ERI, Job Control and Work Engagement (Hypothesis 4)}

Multiple discriminant analysis tested if ERI, job control and work engagement taken together were appropriate for discriminating between the five forms of job satisfaction. After testing the data for outliers and multicollinearity, a classification was conducted with the use of separate-group covariance matrices due to unequal population covariance matrices. In a first run, discriminant analysis separated the five groups of job satisfaction with a Wilks' $\lambda$ of $.606\left(\chi^{2}(12)=202.2, p<.001\right): 44 \%$ of the cases were correctly classified into their original groups. This classification accuracy by the discriminant functions was higher than the proportional random accuracy rate (20\%). Demographic variables were added to improve the discrimination. As we only found significant differences for age and sex, job position was not included. This second run resulted in a better discrimination. The five groups of job satisfaction were separated with a Wilks' $\lambda$ of $.564\left(\chi^{2}(20)=229.6, p<.001\right)$. Three of four discriminant functions had a considerable discriminatory effect. The structure matrix containing within-group correlations between discriminating variables and discriminant functions and the group centroids are shown in Table 4. For the first function (eigenvalue $=.596,84.7 \%$ of variance explained), job control was the most important variable, distinguishing stabilized and progressive satisfaction from the other forms. These two forms show clearly higher job control than the other three forms. The second function (eigenvalue $=.073,10.4 \%$ of variance explained) was defined by age and separated stabilized from progressive satisfaction and fixated dissatisfaction. For the third function (eigenvalue $=.033$, $4.7 \%$ of the variance explained), ERI and work engagement showed the highest correlations. This function separated constructive dissatisfaction from fixated dissatisfaction and resigned satisfaction. The constructive dissatisfied employees showed a higher ERI, but also higher work engagement than the fixated dissatisfied and resigned satisfied ones. Although work engagement and ERI show the largest absolute correlation with Function 3, they also show high loadings on Function 1. This is plausible, as stabilized and progressive satisfied employees show a higher work engagement and lower ERI than the others. Table 5 shows the classification results based on the analysis conducted: $49.9 \%$ of the cases were correctly classified. Comparing the classification of the different forms of job satisfaction showed that constructive dissatisfaction was the most difficult to classify: it was correctly classified in only $31.1 \%$ of the cases and wrongly classified as fixated dissatisfaction in $27.9 \%$ of the cases. Progressive satisfied employees were classified as stabilized satisfied in $22.8 \%$ of the cases and vice versa in $22.9 \%$ of the cases. The best classification was found for fixated dissatisfaction employees, who were correctly classified in $75 \%$ of the cases. Hypothesis 4 is only partly confirmed. After the integration of demographic variables, $49.9 \%$ of the cases were correctly classified.

Table 4. Structure matrix and group centroids for the discriminant functions.

\begin{tabular}{lccc}
\hline & \multicolumn{3}{c}{ Discriminant function } \\
\cline { 2 - 4 } & 1 & 2 & 3 \\
\hline Discriminating variables & & Structure matrix & -.019 \\
\hline Job control & .694 & -.075 & .327 \\
Age & -.057 & .765 & .745 \\
Effort-reward imbalance & -.544 & -.131 & .698 \\
Work engagement & .641 & -.120 & .067 \\
Sex & .140 & .453 & .001 \\
\hline Groups & & Group centroids & .011 \\
\hline Stabilized satisfaction & .530 & .331 & -.192 \\
Progressive satisfaction & .769 & -.381 & .367 \\
Resigned satisfaction & -.575 & -.001 & -.270 \\
Constructive dissatisfaction & -.944 & -.024 & -.137 \\
\hline Fixated dissatisfaction & -1.570 & & \\
\hline
\end{tabular}


Table 5. Classification results.

\begin{tabular}{ccccccc}
\hline \multirow{2}{*}{ Original } & & \multicolumn{5}{c}{ Predicted group membership } \\
\cline { 3 - 7 } & $\mathrm{n}$ & $\begin{array}{c}\text { Stabilized } \\
\text { satisfaction }\end{array}$ & $\begin{array}{c}\text { Progressive } \\
\text { satisfaction }\end{array}$ & $\begin{array}{c}\text { Resigned } \\
\text { satisfaction }\end{array}$ & $\begin{array}{c}\text { Constructive } \\
\text { dissatisfaction }\end{array}$ & $\begin{array}{c}\text { Fixated } \\
\text { dissatisfaction }\end{array}$ \\
\hline Stabilized satisfaction & 131 & $67(51.1 \%)$ & $30(22.9 \%)$ & $14(10.7 \%)$ & $13(9.9 \%)$ & $7(5.3 \%)$ \\
Progressive satisfaction & 101 & $23(22.8 \%)$ & $57(56.4 \%)$ & $3(3.0 \%)$ & $9(8.9 \%)$ & $9(8.9 \%)$ \\
Resigned satisfaction & 90 & $12(13.3 \%)$ & $11(12.2 \%)$ & $42(46.7 \%)$ & $13(14.4 \%)$ & $12(13.3 \%)$ \\
Constructive dissatisfaction & 61 & $7(11.5 \%)$ & $7(11.5 \%)$ & $11(18.0 \%)$ & $19(31.1 \%)$ & $17(27.9 \%)$ \\
Fixated dissatisfaction & 24 & $2(8.3 \%)$ & $1(4.2 \%)$ & $1(4.2 \%)$ & $2(8.3 \%)$ & $18(75.0 \%)$ \\
Ungrouped cases & 4 & $1(25.0 \%)$ & $2(50.0 \%)$ & $0(0 \%)$ & $0(0 \%)$ & $1(25.0 \%)$ \\
\hline
\end{tabular}

Note: $49.9 \%$ of original grouped cases were correctly classified.

\section{Discussion}

\subsection{Differences between the Forms of Job Satisfaction}

Distinguishing the five forms of job satisfaction revealed significant and meaningful differences with respect to health status, work-related health determinants and demographics. We will first discuss the differences between the sub-groups.

Health status: Significant differences between the forms of job satisfaction were found for physical and general health. For mental health, the significance level was just above the $5 \%$ level. The fixated dissatisfied group shows the poorest and the stabilized and progressive satisfied groups show the best health status. The findings are consistent with Semmer (2002) and Wegge and Neuhaus (2002).

Work-related determinants of health: Compared to the other forms of job satisfaction, the stabilized and progressive satisfied groups showed significantly better ERI, job control and work engagement. In contrast to Baumgartner and Udris (2006), but like Wegge and Neuhaus (2002) and Büssing et al. (1998, 1999), we found that high job control characterized the stabilized and progressive satisfied groups. While we expected higher work engagement for the progressive than for the stabilized satisfaction group, only marginal differences were actually found. Thus, the stabilized and progressive forms of job satisfaction were not differentiated by ERI, job control or work engagement. The resigned satisfied group showed medium values for ERI, job control and work engagement. The hypotheses were confirmed with respect to ERI, but we expected the resigned satisfied employees to have lower work engagement and job control. Constructive dissatisfaction was related with the poorest values for ERI. Job control was also low and work engagement moderate. We expected higher values of job control (Büssing et al., 1998, 1999) and work engagement. The observed low control might be explained by the item formulation: on the pattern of active problem-solving behavior, the model should distinguish those with control (constructive dissatisfied) from those without control (fixated dissatisfied). At present, the item formulation locates control outside the person. Further, we assume that a high ERI in combination with low job control leads to moderate work engagement: constructive dissatisfaction is characterized by a high need for advancement due to significant annoying issues, but low job control hinders any change of the situation, leading to moderate work engagement. Convergent with our results, Wegge and Neuhaus (2002) found that low levels of job control correlated with constructive dissatisfaction. As hypothesized, fixated dissatisfied employees showed the lowest values for all variables except for ERI, where constructive dissatisfied employees showed slightly poorer values.

Demographic variables: The stabilized satisfied group more often comprised women and older people. This has also been found before (Bruggemann, 1976; TransferPlus AG, 2013; Wegge \& Neuhaus, 2002). Progressive satisfied employees were younger, and managers were over-represented in this group (although not significantly). Concerning age, Bruggemann (1976) and TransferPlus AG (2013) reported the same results. A higher percentage of managers in this group was also shown by TransferPlus AG (2013). Higher status (Wegge \& Neuhaus, 2002), higher income (Bruggemann, 1976) and higher education (Bruggemann, 1976; TransferPlus AG, 2013) are plausibly related with progressive satisfaction, as they are correlated with higher job position. The resigned satisfied group was more likely to comprise unskilled people or trainees. Bruggemann (1976) and Trans- 
ferPlus AG (2010) also found that lower education levels was related with resigned satisfaction. The constructive dissatisfaction group could not be characterized by sex, age or job position. Men were not significantly over-represented, as Bruggemann (1976) also showed. In the fixated dissatisfied group, aged 36 - 50, men and employees were over-represented (see Table 1). There were no clear findings for this group from previous research. For all five forms of job satisfaction, our results were consistent with previous findings. Furthermore, we concur with the U-shaped relationship between age and job satisfaction: middle-aged employees were overrepresented in the group of fixated dissatisfied and both younger and older people were more satisfied, although in different ways. Older people were more stabilized and younger ones were more likely to be in the progressive satisfied group.

\subsection{Use of the Discriminatory Function}

The discrimination of the five forms of job satisfaction by job control, ERI, work engagement and demographic variables resulted in three functions. Job control discriminated the satisfied (stabilized and progressive satisfaction) from the indistinct dissatisfied (resigned satisfaction, constructive and fixated dissatisfaction) groups (see Figure 1). However, work engagement and ERI had high loadings on this function too, as hypothesized and showed by the differentiation analysis. Age discriminated most between stabilized and progressive satisfaction. ERI and work engagement separated the constructive dissatisfied from the fixated dissatisfied and resigned satisfied groups. The constructive dissatisfied employees showed a higher ERI, but also higher work engagement than fixated dissatisfied and resigned satisfied employees.

Overall only half of the cases were correctly classified. Most misclassifications occurred in differentiating the constructive and fixated dissatisfied. This is consistent with the results of the variance analysis, which revealed a higher work engagement for the constructive dissatisfied group to be the only significant difference between those two forms. The differentiation between stabilized and progressive forms of job satisfaction is also difficult. Here, tests comparing differences between groups only showed significant differences with respect to age and sex. It may be necessary to add further discriminating variables. Alternatively, the five forms of job satisfaction may be difficult to distinguish by a forced-choice item, especially as the item formulation of constructive dissatisfaction does not conform ideally to the model's theory.

\subsection{Limitations}

This study was designed as a field study. Therefore it was not possible to measure the job satisfaction form with the FEAT of Ferreira (2009) or to use a more sophisticated job satisfaction measure to compare the results. This would have enlarged the questionnaire to an improper extent.

A further limitation is our sample size. Some cells in Table 1 have a low n, especially the unskilled workers and trainees. However, unskilled workers and trainees represent at least $9.5 \%$ of the entire sample. The sample contained more progressive and fewer resigned satisfied employees than the distribution in the Swiss population determined by TransferPlus AG. This was probably due to the fact that the data was collected in the context of an occupational health intervention. These companies are engaged in a process of occupational health change and may thus differ in their structure and culture from the rest of the population. For similar reasons, the generalization of the results is limited, as most of the sample (85\%) derives from non-profit organizations. Thus, the results should be compared to a sample of companies from the private sector.

\section{Conclusion}

\subsection{Use of the Model for Occupational Health Interventions}

Although a linear pattern in the result is apparent, some differential patterns of health status, ERI, job control, work engagement and demographics in the five forms of job satisfaction facilitate the definition of specific target groups of occupational health interventions. Stabilized satisfied employees tend to be older and therefore are a special target group for health-oriented interventions at work. While the progressive satisfied employees are highly engaged, their mental health is moderate. There may be a risk of burnout or other mental health problems in this group. At the same time, this group is likely to become actively involved in occupational health interventions. The resigned satisfied group showed intermediate values for health, ERI and job control and lower values for work engagement. These employees are easily overseen because they seem satisfied at first sight, but only 
because of a decrease of aspiration level. High levels of job satisfaction in global satisfaction measures may be due to a large number of resigned satisfied employees. This group should be specifically animated for occupational health interventions. Constructive dissatisfied employees showed lower health values with the exception of mental health, which was on a good level. Although they experience ERI and do not have much job control, they are still moderately engaged. This group could act as an informant and producer of ideas in occupational health interventions. Fixated dissatisfaction is associated with lowest health levels and also lowest values of work-related determinants of health. It is likely that less engaged employees in the fixated dissatisfied (similar to the resigned satisfied) group need specific animation.

\subsection{Further Research}

The results suggest that the item formulation for constructive dissatisfaction should be revised in order to further accentuate active problem-solving behavior by the individual. A possible item reformulation could be: "I am not satisfied with my job, because there are important issues that annoy me. But I think I will find ways to change these issues in future". This item formulation should be validated in a sample containing more companies from the private sector.

Intervention studies should analyze how employees characterized by different forms of job satisfaction differ in their degree of readiness to change, participation in interventions and perceived improvement of working environment after interventions and finally, how such interventions can move employees to healthier forms of job satisfaction.

\section{Acknowledgements}

We thank Silvia Deplazes, dipl. Psych. MBA, and Katharina Lehmann, PhD, for their contributions in data collection, Ivars Udris, em. Prof. ETHZ, for his contributions to the study conception, Alois Tschopp, PhD, for statistical advice and Verena Friedrich, PhD, for her feedback on the paper.

\section{References}

Baron, H. (1996). Strengths and Limitations of Ipsative Measurement. Journal of Occupational and Organizational Psychology, 69, 49-56. http://dx.doi.org/10.1111/j.2044-8325.1996.tb00599.x

Baumgartner, C., \& Udris, I. (2006). Das “Zürcher Modell” der Arbeitszufriedenheit—30 Jahre “Still Going Strong”. In L. Fischer (Ed.), Arbeitszufriedenheit. Konzepte und Empirische Befunde. Göttingen: Hogrefe.

Bond, F. W., \& Bunce, D. (2003). The Role of Acceptance and Job Control in Mental Health, Job Satisfaction, and Work Performance. Journal of Applied Psychology, 88, 1057-1067. http://dx.doi.org/10.1037/0021-9010.88.6.1057

Bruggemann, A. (1974). Zur Unterscheidung Verschiedener Formen von “Arbeitszufriedenheit”. Arbeit und Leistung, 28, 281-284.

Bruggemann, A. (1976). Zur Empirischen Untersuchung Verschiedener Formen von Arbeitszufriedenheit. Zeitschrift für Arbeitswissenschaften, 30, 71-74.

Büssing, A. (1992). A Dynamic View of Job Satisfaction in Psychiatric Nurses in Germany. Work \& Stress, 6, $239-259$. http://dx.doi.org/10.1080/02678379208259956

Büssing, A. (2002). Motivation and Satisfaction. In A. Sorge (Ed.), Organization (pp. 371-387). London: Thomson Learning.

Büssing, A., \& Bissels, T. (1998). Different Forms of Work Satisfaction: Concept and Qualitative Research. European Psychologist, 3, 209-218. http://dx.doi.org/10.1027/1016-9040.3.3.209

Büssing, A., Bissels, T., Fuchs, V., \& Perrar, K.-M. (1999). A Dynamic Model of Work Satisfaction: Qualitative Approaches. Human Relations, 52, 999-1028. http://dx.doi.org/10.1177/001872679905200802

Büssing, A., Herbig, B., Bissels, T., \& Krüsken, J. (2006). Formen der Arbeitszufriedenheit und Handlungsqualität in Arbeits- und Nicht-Arbeitskontexten. In L. Fischer (Ed.), Arbeitszufriedenheit. Konzepte und Empirische Befunde (pp. 135159). Göttingen: Hogrefe.

Clark, A. E. (1997). Job Satisfaction and Gender: Why Are Women So Happy at Work? Labour Economics, 4, 341-372. http://dx.doi.org/10.1016/S0927-5371(97)00010-9

Clark, A. E., Oswald, A., \& Warr, P. (1996). Is Job Satisfaction U-Shaped in Age? Journal of Occupational and Organizational Psychology, 69, 57-81. http://dx.doi.org/10.1111/j.2044-8325.1996.tb00600.x 
Faragher, E. B., Cass, M., \& Cooper, C. L. (2005). The Relationship between Job Satisfaction and Health: A Meta-Analysis. Journal of Occupational \& Environmental Medicine, 62, 105-112. http://dx.doi.org/10.1136/oem.2002.006734

Ferreira, Y. (2009). FEAT_Fragebogen zur Erhebung von Arbeitszufriedenheitstypen: Zukunftsperspektive für das Züricher Modell. Zeitschrift für Arbeits- und Organisationspsychologie, 53, 177-193. http://dx.doi.org/10.1026/0932-4089.53.4.177

Gandek, B., Ware, J. E., Aaronson, N. K., Apolone, G., Bjorner, J. B., Brazier, J. E., et al. (1998). Cross-Validation of Item Selection and Scoring for the SF-12 Health Survey in Nine Countries: Results from the IQOLA Project. Journal of Clinical Epidemiology, 51, 1171-1178. http://dx.doi.org/10.1016/S0895-4356(98)00109-7

Ganster, D. C. (1989). Manual of the Generalhealth Questionnaire. Final Report to the National Institute of Occupational Safety and Health (Contract No. 88-79187). Cincinnati: National Institute of Occupational Safety and Health.

Gesundheitsfoerderung Schweiz (2004). KMU-Vital, Programm fuer Gesunde Betriebe. www.kmu-vital.ch www.pme-vital.ch

Karasek, R. (1990). Lower Health Risk with Increased Job Control among White Collar Workers. Journal of Organisational Behaviour, 11, 171-185. http://dx.doi.org/10.1002/job.4030110302

Moller, L., Kristensen, T. S., \& Hollnagel, H. (1996). Self Rated Health as a Predictor of Coronary Heart Disease in Copenhagen, Denmark. Journal of Epidemiology and Community Health, 50, 423-428. http://dx.doi.org/10.1136/jech.50.4.423

Nagy, M. S. (2002). Using a Single-Item Approach to Measurefacet Job Satisfaction. Journal of Occupational and Organizational Psychology, 75, 77-86. http://dx.doi.org/10.1348/096317902167658

Schaufeli, W. B., \& Bakker, A. B. (2003). The Utrecht Work Engagement Scale (UWES): Test Manual. Utrecht: Utrecht University.

Schaufeli, W. B., Taris, T. W., \& van Rhenen, W. (2008). Workaholism, Burnout, and Work Engagement: Three of a Kind or Three Different Kinds of Employee Well-being? Applied Psychology: An International Review, 57, 173-203. http://dx.doi.org/10.1111/j.1464-0597.2007.00285.x

Semmer, N. K. (2002). Job Satisfaction: A Central but Underestimated Concept in the Psychology of Work. Hesse: University of Giessen.

SF-12v2 Health Survey (2000). German Standard Version for Switzerland: Health Assessment Lab, Medical Outcomes Trust and Quality Metric Invorporated.

Siegrist, J., \& Peter, R. (1996). Effort-Reward Imbalance: Fragebogen zur beruflichen Situation II (Kurzversion). Düsseldorf: Universität Düsseldorf.

Siegrist, J., Starke, D., Chandola, T., Godin, I., Marmot, M., Niedhammer, I., et al. (2004). The Measurement of EffortReward Imbalance at Work: European Comparisons. Social Science \& Medicine, 58, 1483-1499. http://dx.doi.org/10.1016/S0277-9536(03)00351-4

SPSS for MAC Rel. 17.0.1 (2008). Chicago: SPSS Inc.

TransferPlus AG (2013). Arbeitszufriedenheit 2013. Optimistischere Töne bei Schweizer Erwerbstätigen. Stansstad. www.transferplus.ch

Van Vegchel, N., De Jonge, J., Bosma, H., \& Schaufeli, W. B. (2005). Reviewing the Effort-Reward Imbalance Model: Drawing up the Balance of 45 Empirical Studies. Social Science \& Medicine, 60, 1117-1131. http://dx.doi.org/10.1016/j.socscimed.2004.06.043

Wanous, J. P., Reichers, A. E., \& Hudy, M. J. (1997). Overall Job Satisfaction: How Good Are Single-Item Measures? Journal of Applied Psychology, 82, 247-252. http://dx.doi.org/10.1037/0021-9010.82.2.247

Ware, J. E., Kosiniski, M., Turner-Bowker, D. M., \& Gandek, B. (2002). How to Score Version 2 of the SF-12 Health Survey (With a Supplement Documenting Version 1). Lincoln, RI: Quality Metric Incorporated.

Wegge, J., \& Neuhaus, L. (2002). Emotionen bei der Büroarbeit am PC: Ein Test der “Affective Events”-Theorie. Zeitschrift fur Arbeits- und Organisationspsychologie, 46, 173-184. http://dx.doi.org/10.1026//0932-4089.46.4.173

Ziegler, R., \& Schlett, C. (2013). Formen der Arbeitszufriedenheit: Untersuchungenzur Validität der Selbstzuordnungsmethodesowiezu Unterschieden in der Valenz der Arbeit, der Arbeitssituation und der dispositionalen Affektivität. Zeitschrift fur Arbeits- und Organisationspsychologie, 57, 51-76. http://dx.doi.org/10.1026/0932-4089/a000107 
Scientific Research Publishing (SCIRP) is one of the largest Open Access journal publishers. It is currently publishing more than 200 open access, online, peer-reviewed journals covering a wide range of academic disciplines. SCIRP serves the worldwide academic communities and contributes to the progress and application of science with its publication.

Other selected journals from SCIRP are listed as below. Submit your manuscript to us via either submit@scirp.org or Online Submission Portal.
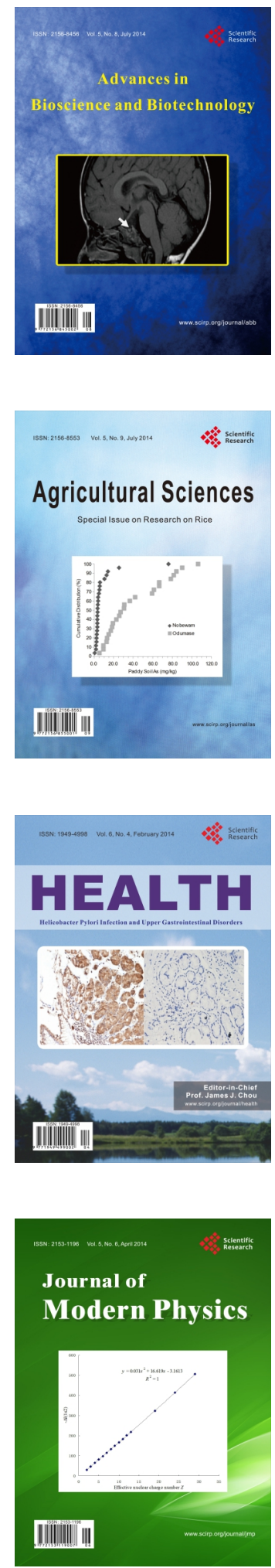
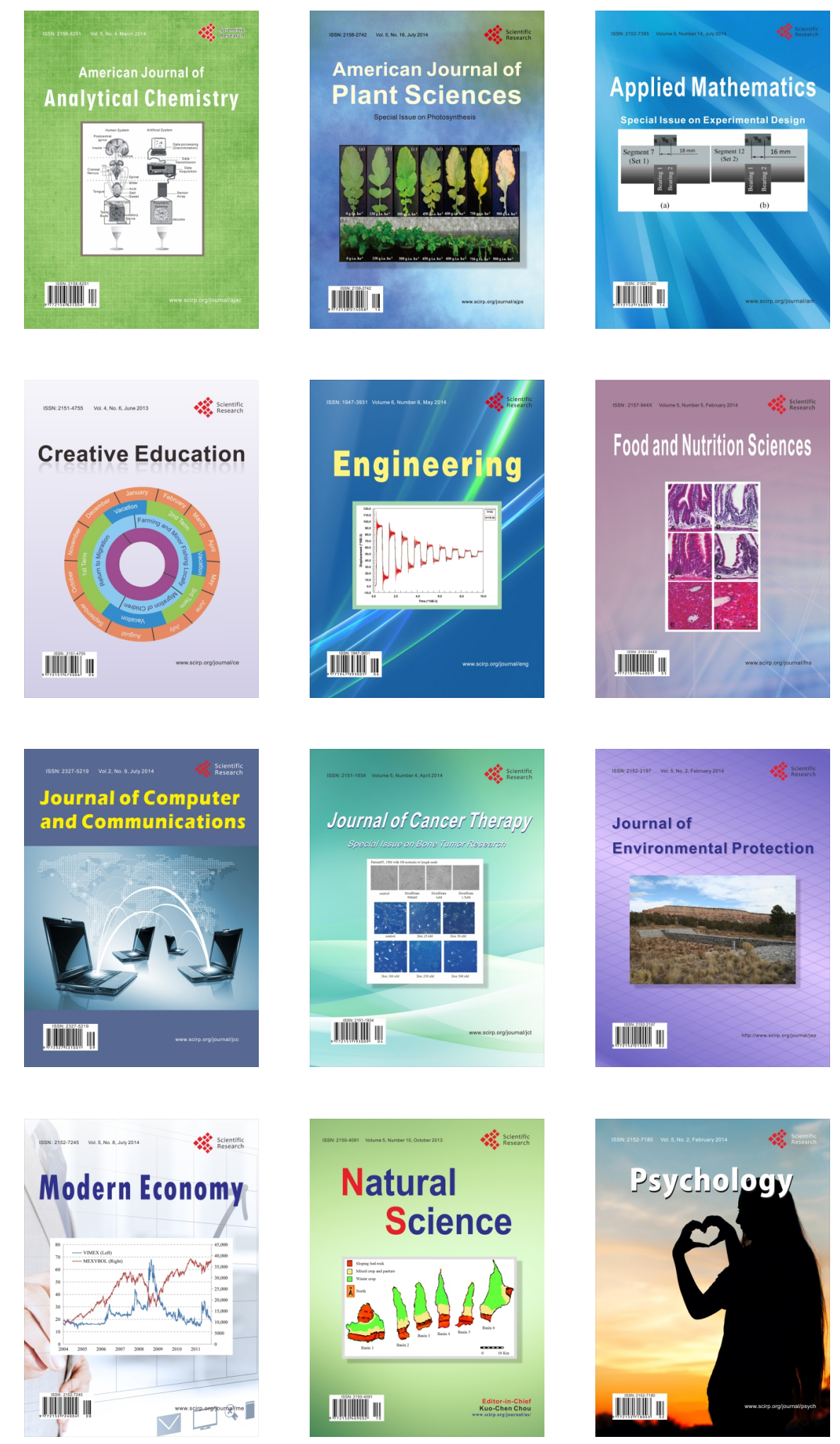